\title{
PADRÕES AFETIVOS NA FAMÍLIA E EMPRESA FAMILIAR*
}

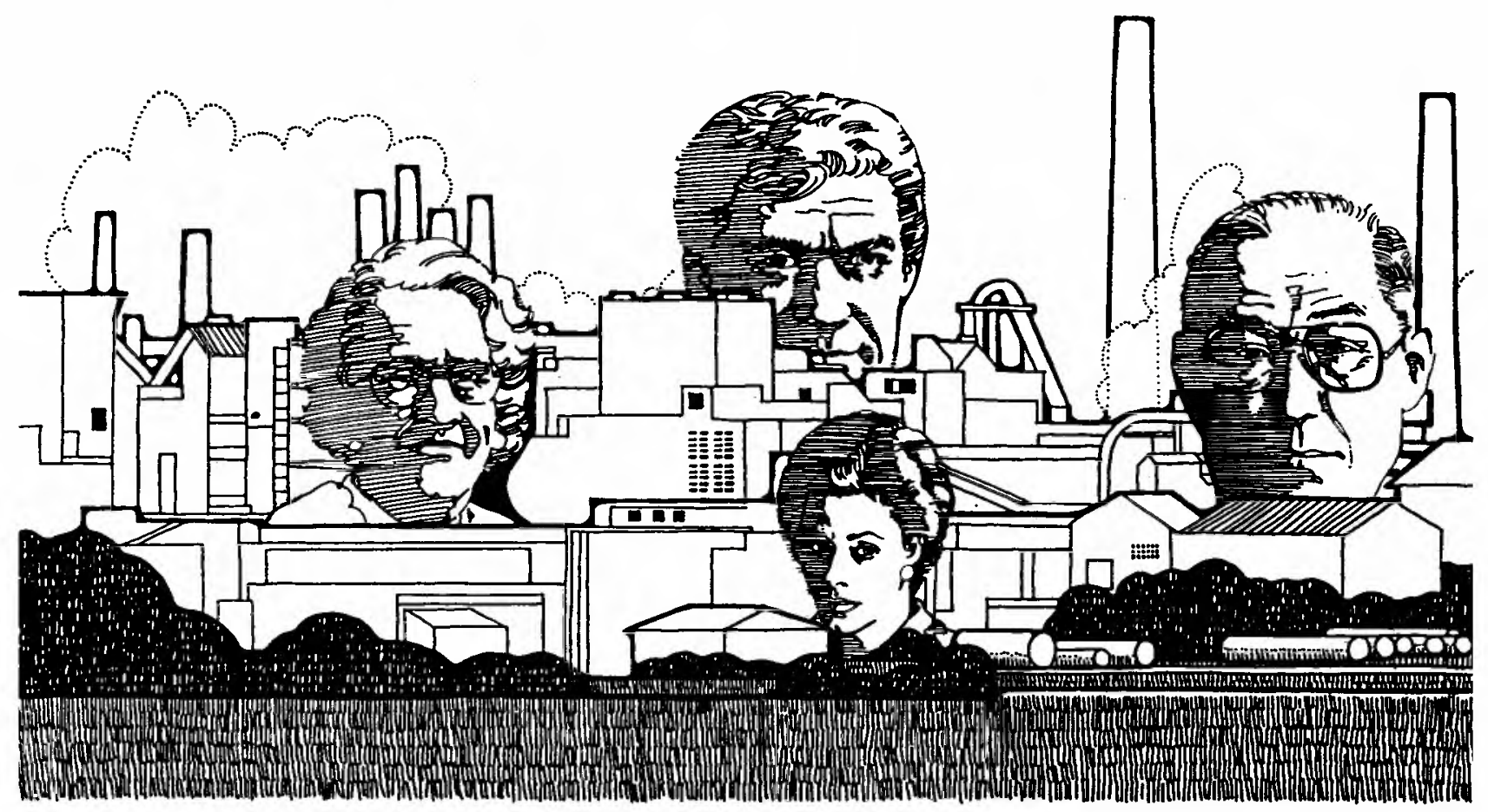

Arakcy Martins Rodrigues

Professora Titular de Psicologia do Departamento de

Fundamentos Sociais e Jurídicos da Administração da EAESP/FGV.

* RESUMO: O artigo apresenta os resultados de uma pesquisa que parte de duas hipóteses: a) as preferências afetivas e a convivência na familia extensa se voltam preferencialmente para o lado materno da familia; b) as empresas familiares reúnem parentes do lado paterno, isto é, a composição da propriedade das empresas familiares se dá majoritariamente entre irmãos homens ou pai e filhos homens.

Confirmadas as duas hipóteses, configurar-se-ia, entre outras já estudadas, uma incompatibilidade entre a esfera da familia e a da empresa, no caso das empresas familiares.

Considerando que o mesmo grupo de pessoas está envolvido num e noutro dos sistemas (familia e empresa), tal incompatibilidade não deixará, por certo, de gerar efeitos.

* PALAVRAS-CHAVE: Empresa familiar, preferências afetivas na famulia, composição das empresas familiares, incompatibilidade.
* ABSTRACT: The research upon which this article is based originates in two hypotheses: a) emotional preferences and companionship in the extended family are generally oriented towards the maternal side of the family; $b$ ) family firms bring together relatives from the paternal side, this translates into the property of family firms being held principally by brothers or by father and brothers.

The two hypotheses confirmed, there occurs within family firms, among other phenomena already studied, an incompatibility between the family sphere and the sphere of the firm.

Considering that the same group of people is involved in each of these spheres (family and firm), such an incompatibility, produces effects.

* KEY WORDS: Family firms, emotional preferences in the family, composition of family firms, incompatibility.

\footnotetext{
* Quero manifestar meu agradecimento à inestimável ajuda que me foi dada no trabalho de campo pelos seguintes colegas, professores da FGV: Maria Christina Siqueira de Souza Campos, Maria José Tonelli, Ofélia de Lanna Sette Torres, Seiji Uchida e Sigmar Malvezzi.
} 


\section{INIRODUÇĀo}

0 $s$ estudos sobre empresas familiares são bastante numerosos. Graças a eles, contamos hoje com um conjunto de conhecimentos que são de grande valia nos diagnósticos e prognósticos possíveis para esse tipo de organização.

Comecemos pela definição. Segundo João Bosco Lodi ${ }^{1}$, o conceito só cabe a partir da segunda geração do fundador. Durante o período de gestão e propriedade deste, podemos falar de empresa pessoal.

Outras conclusões já foram bastante veiculadas: as empresas familiares menores vão melhor; entre estas, mesmo as bem-sucedidas raramente podem manter a família inteira; é difícil, numa sociedade moderna e aberta como a atual, preservar uma tradição ocupacional numa família; as crianças são desde muito cedo submetidas a uma educação e disciplina especiais; o trabalho, o lazer e a vida familiar dos ocupantes dos cargos das empresas familiares têm que estar integrados, o que traz marcas muito características para suas vidas; pertencer à família não é o suficiente para satisfazer as exigências de cargos gerenciais em empresas modernas; a competência de um membro da família será sempre discutível (isto é, restará sempre a pergunta: "Ele conseguiria a mesma ascensão profissional em outra empresa" $)^{2}$; há casos de competências "construídas" pela própria empresa (e família). Isto é, todas as estratégias (inclusive especialização no exterior, implantação imediata das idéias trazidas de lá, todos os cuidados para que sejam um sucesso etc.) que levam ao reconhecimento de uma competência excepcional são inteligentemente postas em prática na formação do "sucessor superdotado" como se, só por coincidência, ele fosse filho do fundador. ${ }^{3}$ Ao contrário, mesmo o sucessor realmente qualificado ficará sempre em dúvida quanto às suas verdadeiras habilidades gerenciais, internalizando parcialmente o rótulo que a opinião pública lhe confere; a família pode "considerar como seu produto predominante o suprimento de homens como executivos de alto nível para uma empresa familiar. Neste caso, os insumos principais serão bebês de sexo masculino em intervalos corretos".

Os padrões de comportamento grupal são diferentes para uma família e para uma empresa. Miller e Rice afirmam: "A força propulsora da indústria e do comércio numa economia capitalista é a competição (...) Em Contraste, a força propulsora de uma familia é sua unidade - uma unidade baseada na repressão ou negação do conflito interno. A competição entre os membros deve manter-se baixa. Numa empresa familiar, a cultura interna não competitiva da familia e a realidade externa de competição são freqüentemente incompativeis". ${ }^{5}$

Poderíamos ir muito longe no arrolamento das influências mútuas entre família e empre$\mathrm{sa}$, quando essas duas instituições formam uma empresa familiar. Muito freqüentemente, as tentativas de "adaptação" prejudicam ambas, família e empresa. Há que lembrar, ainda, das incompatibilidades básicas, que afetariam estruturalmente o padrão de comportamento requerido para a sobrevivência de uma e outra instituição, como é o caso da competitividade versus unidade no exemplo acima.

Apenas os títulos de alguns trabalhos na área são suficientes para vislumbrarmos a complexidade da adaptação entre as duas realidades em jogo. Citemos alguns: "Does father really know best?"6; "Family planning may help head off generation gaps"; "Cut the baby in half?".

O constructo teórico que, na nossa opinião, melhor abarca os incontáveis aspectos contidos no problema da fusão empresa-família foi o elaborado por autores da Escola Sócio-técnica, especialmente os já citados Miller e Rice. Refere-se ao modelo de fronteiras coincidentes, do qual a empresa familiar é o caso-tipo. Teríamos, então, dois sistemas cujas fronteiras se justapõem. Os mesmos autores já haviam apontado as dificuldades que encontramos em utilizar as hipóteses da Teoria das Organizações - toda ela construída a partir de estudos empíricos realizados no mundo fabril, onde as fronteiras físicas e organizacionais coincidem - em outros tipos de organização onde tal coincidência não ocorre (setor de vendas, aviação comercial etc.)

Na empresa familiar, com a coincidência de outras duas fronteiras - a do sistema familiar e a do sistema empresarial - um terceiro tipo de configuração aparece. Existem duas tarefas e conseqüentemente dois sistemas de atividades na empresa familiar, "mas aqueles que executam as tarefas - os recursos humanos nos dois sistemas - constituem um único grupo de vivência. Conseqüentemente, a força da fronteira de vivência do grupo é afetada por aquilo que acontece em ambos os sistemas de atividade e, ao longo da fronteira comum do grupo de vivencia, as atividades de cada sistema são afetadas pelas do outro". ${ }^{9}$

Neste artigo, é nosso propósito apontar especificamente uma das incompatibilidades entre esses dois sistemas com fronteiras coincidentes, que é a empresa familiar; os padrões afetivos na família e a composição da empresa familiar. 


\section{OBJETNOS E HIPÓTESES}

Preliminarmente, devemos esclarecer dois pontos. Em primeiro lugar, é preciso lembrar que, se uma empresa só pode ser qualificada como familiar a partir da segunda geração do fundador, já estaremos às voltas, não com a família nuclear (pai, mãe, irmãos), mas com a família extensa (tios, primos, avós etc.). Em segundo lugar, deve-se salientar o fato de que a empresa familiar, na maior parte das vezes, é um "negócio entre homens". Através de vários tipos de "arranjos" (o principal deles consistindo, provavelmente, numa distribuição da herança que deixa os bens imóveis para as filhas e as empresas vivas para os filhos) que mereceriam uma pesquisa à parte, encontramos os membros de sexo masculino à frente da empresa, nas sucessivas gerações do ciclo vital dessa organização. (Repetimos que estamos falando da configuração modal nesse tipo de empresa.)

Em relação à família extensa existem, para cada indivíduo, dois "lados": o materno e o paterno. As principais hipóteses da pesquisa empírica que fundamenta este trabalho são as seguintes: a circulação do afeto familiar se dá preferencialmente com o lado materno; a empresa familiar, ao contrário, é geralmente composta por parentes do lado paterno.

A discussão das razões que levam à inclinação para o lado materno, do ponto de vista afetivo, não cabe nos limites deste artigo. Poderíamos imaginar interpretações possíveis, a partir de certas formulações de outros autores ou por dedução, estendendo para este tópico fenômenos já estudados em outras áreas:

- é a mulher que se encarrega do trabalho simbólico e afetivo na divisão sexual do trabalho;

- a competição entre o patriarcalismo e o matriarcalismo está aparentamente decidida com uma vitória do patriarcalismo, mas a luta prossegue, e emite sinais de sua existência, um dos quais poderia ser o maior afeto e convivência com o lado materno. Estaríamos, pois, diante do poder feminino;

- a mãe representa o afeto, a simbiose, o indiferenciado, enquanto o pai representa a palavra e a lei, numa interpretação lacaniana. Assim, o feminino e o masculino ficariam configurados, no nosso caso, pelos pólos afeto familiar vs. empresa;

- a valorização do homem em nossa sociedade poderia estar na raiz de uma rejeição básica, por parte da família do homem, contra a mulher com quem ele se casa. Esta, por sua vez, se defenderia dessa desvalorização, res- pondendo com outra do mesmo tamanho; estaríamos, nesta hipótese, diante de um caso de dupla rejeição.

\section{INFORMAÇŌES SOBRE A PESQUISA}

As hipóteses já mencionadas - afetividade na família voltada para o lado materno e empresas familiares compostas pelo lado paterno - foram verificadas através de uma pesquisa empírica; a coleta de dados se deu através de um questionário auto-aplicável, contendo as questões que constam do anexo 1.

a) a pergunta 1 investiga co-habitação com parentes da família extensa;

b) as perguntas 2, 3, 4 e 5 foram elaboradas para medir as preferências afetivas na família e a convivência familiar;

c) segue-se uma pergunta ( $n^{\circ}$ 6) sobre a composição de empresas familiares eventualmente presentes;

d) seguem-se perguntas sobre variáveis consideradas virtualmente efetivas em relação ao objeto de estudo: sexo, idade, origem (etnia) dos pais e avós (questões 7, 8 e 9);

e) finalmente, a pergunta 10 trata de verificar se existem ambos os lados da família extensa e quais os parentes que habitam na mesma cidade do entrevistado.

Chamamos a atenção para o fato de a pergunta de número 2 ("Excluindo seus pais e irmãos, quais os três parentes de quem você mais gosta?") acarretar três respostas; da mesma forma, a pergunta $n^{0} 4$ deixa espaço para três respostas.

A amostra não seguiu os rigores geralmente impostos para um teste de hipótese quantitativo. Algumas classes de alunos, da graduação da FGV e da PUC foram escolhidas para a aplicação do questionário. A escolha das classes não foi produto de sorteio, mas foi motivada pela viabilidade: levantamos os dados junto a turmas para as quais colegas que se dispuseram a ajudar no trabalho de campo davam aulas durante o primeiro semestre de 1991.

Obtivemos 398 questionários preenchidos e apenas dois casos de rejeicão.

Consideramos todas as conseqüências de trabalharmos com essa amostra e concluímos o seguinte:

a) os alunos, pelas características das escolas em que estudam, pertencem à classe média alta e à classe alta. Esse viés foi consentido, uma vez que nosso interesse por empresas familiares de pelo menos médio porte estão situadas justamente nessas classes sociais; 
b) outro viés óbvio refere-se à faixa etária dos respondentes. Também neste caso pareceunos muito adequada aos nossos propósitos essa seleção. Indivíduos de ambos os sexos, ainda solteiros $\mathrm{cm}$ sua quase totalidade, mas numa idade que já permite total autonomia para assumir suas preferências afetivas por determinados parentes e, ademais, autonomia para visitar, telefonar ou sair com as pessoas de sua preferência dentro da família extensa pareceram-nos estar na etapa do ciclo vital mais propícia para serem submetidos a esse tipo de investigação;

c) quanto ao fato de a escolha das classes de alunos ter sido norteada pela facilidade operacional, não conseguimos imaginar nenhum viés específico que pudesse decorrer desse procedimento. Estamos convencidos de que, com uma amostra resultante de um sorteio das classes, os resultados seriam os mesmos.

Construímos uma subamostra sobre a qual fizemos incidir alguns crucamentos, entre os que analisaremos ao longo deste trabalho. Elaboramos tal subamostra escolhendo aqueles casos cuja família nuclear mora em são Paulo e que possuem todos os tipos de parentes de ambos os lados morando igualmente em São Paulo. Dos 398 casos estudados, 66 se incluíam nessas condições: são os componenles da subamostra que, como já salientamos, scrá utilizada para o estudo de algumas variáveis.

Evidentemente, esse lipo de amostra nâo pormitiu um tratamento estatístico dos resullados numéricos. Entretanto, o número de questionários, somado ao lato de termos assumido os viéses presentes, e à consistência en- contrada nas respostas às diversas perguntas que abordavam de ângulos diferentes o mesmo tema, fornecem fortes indicações a favor das hipóteses principais que nortearam a pesquisa empírica que fundamenta este artigo.

\section{ANÁLISE DOS RESULTADOS}

A tabela 1 mostra os tipos de agrupamento domiciliar que encontramos em nossas unidades amostrais.

Chama-nos a atenção, nessa distribuição:

a) a diferença entre o número de domicílios monoparentais com a presença só da mãe (26 casos, 6,53\%) e o de monoparentais com a presença só do pai (dois casos, $0,50 \%$ );

b) a diferença entre o número de casos em que a avó materna mora com a família nuclear (19 casos, 4,77\%) e o número de casos de avo paterna nas mesmas condiçöes (cinco casos, $1,26 \%)$ e apenas um caso $(0,25 \%)$ de avô paterno morando com a família nuclear.

Somando-se as familias nuclcares cue abrigam um ou mais parentes do lado materno, temos 27 casos $(6,78 \%)$ contra onze casos $(2,76 \%)$ de parentes paternos.

$\Lambda$ pergunta de número 2 - "Excluindo seus pais $\mathrm{e}$ irmãos, quais os três parentes de quem você mais gosta?" - tem, como já apontamos, três respostas. A distribuição das respostas dadas em primeiro lugar para csta pergunta está na tabela 2. A tabela $2 a$, por sua vez, contém a soma de todos os parentes da tabela 2 por lado de parentesco.

Queremos aproveitar a tabela 2, pelo lato de ser a única - dentre as que virào a seguir -

\section{Tabela 1: Distribuição dos tipos de agrupamento domiciliar}

\begin{tabular}{|c|c|c|}
\hline com tamilia nuclear ( $\mathrm{par}$, mäe, inmáos) & 228 & 57.290 \\
\hline com antigos, imäos, primos & 54 & $13,57 \%$ \\
\hline com lamlla monoparental (mâe) & 26 & $6,53 \%$ \\
\hline Lon famíia ncicleat mais avo mater a & 19 & $4,77 \%$ \\
\hline con oonjuge flthos & 15 & $3,77 \%$ \\
\hline em casa de parenles & 15 & $3,77 \%$ \\
\hline sozinnos & +3 & $3,27 \%$ \\
\hline com familia nuc ear mais um oli dos parentos do lado rraterro & 8 & $2,01 \%$ \\
\hline em pensionato ou republica & Lets & $126 \%$ \\
\hline Com familia nuclear nials avó palerra & 5 & $126 \%$ \\
\hline con familia fuclear mais um ou dois parentes do lado paterno & $4 \quad 4 \quad-\quad$ & $100 \%$ \\
\hline cont lamilia mon oparental (pai) & ? & $0,50 \%$ \\
\hline com namorado & 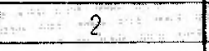 & $0,50 \%$ \\
\hline com tartil ia ruclear mais avô patano & 1 & $0,25 \%$ \\
\hline com faníla monoparental (măe) mais um parenes do laco mateno & $1+1 \quad 1$ & $\begin{array}{r}0,25 \% \\
\end{array}$ \\
\hline Totril & 348 & $100,00 \%$ \\
\hline
\end{tabular}


com a informação completa da tabulação das respostas, para chamar a atenção sobre outra característica importante dos dados da pesquisa. Separando-se os parenles apontados por gênero, temos 267 alusões a parentes femininos e 188 a masculinos. O padrão se repete nas distribuições das respostas às demais perguntas sobre afelividade e convivência. Fste fato parece confirmar a hipótese segundo a qual o afeto familiar encontra seu objeto preferencialmente em mulheres. A polarização por gênero que acabamos de apontar não altera nossa hipótese principal, uma vez que, teoricamente, devem existir tantas mulheres (tias, primas, avós) no lado paterno quanto no lado materno da família extensa. Assim, a polarização por gênero nos levaria a afirmar: o afeto familiar se dirige preferencialmente às mulheres da familia extensa e, dentre estas, preferencialmente às mulheres do lado matemo da família.
O segundo parente apontado, entre os três solicitados pela primeira pergunta, apresenta, para os cinco mais freqüentes, a distribuição contida na tabela 3 .

Comparados com a distribuiçăo do primeiro parente apontado como o mais querido (que transcrevemos integralmente na tabela 2), vemos que os cinco primeiros lugares na tabcla 3 não diferem muito da classificação anterior; é importante observar que na última distribuição (tabela 3) não há nenhum parente do lado paterno entre os cinco primeiros colados.

A tabcla $3 a$ mostra as respostas agrupadas por lado de parentesco. Aí se vê que cai o número que indica a soma dos parentes do lado materno, em relação à resposta anterior (tabela 2 a), mas a diferença fica dividida, nesta segunda resposta, entre a soma dos parentes do lado paterno c os casos sem resposta.

Tabela 2: Distribuição da primeira resposta sobre parentes de quem mais gosta

\begin{tabular}{|c|c|c|}
\hline avó materna & 98 & $24,13 \%$ \\
\hline tla matcrna & 78 & $19,61 \%$ \\
\hline prima naterna & 34 & $8,54 \%$ \\
\hline avó paterna & 32 & $8,04 \%$ \\
\hline tio materno & 29 & $7,29 \%$ \\
\hline Lla paterna & 24 & $6,03 \%$ \\
\hline avô rnaterno & 21 & $5,28 \%$ \\
\hline primo nialemo & 19 & $477 \%$ \\
\hline 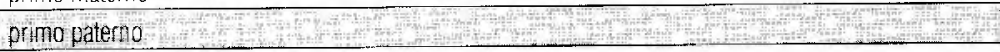 & 17. & $4,27 \%$ \\
\hline avô páterino & 14 & $352 \%$ \\
\hline top paterno & 11 & $276 \%$ \\
\hline prima paterna & 7 & $1,75 \%$ \\
\hline sobriahos & 2 & $0,50 \%$ \\
\hline padrinho (lado maternu) & 1 & $0,25 \%$ \\
\hline sem resposta & 11 & $2,76 \%$ \\
\hline Total & 398 & $100,00 \%$ \\
\hline
\end{tabular}

Tabela 2a: Soma das respostas da tabela 2 por lado de parentesco

\begin{tabular}{|l|c|c|}
\hline Sama dos parentes do lado materno & 280 & $70,36 \%$ \\
\hline Soma dos parentes do lado paterno & 105 & $26,38 \%$ \\
\hline Soma de sobrinhos & 2 & $0,50 \%$ \\
\hline Sem resposta & 11 & $2,76 \%$ \\
\hline Total & 398 & $100,00 \%$ \\
\hline
\end{tabular}

Tabela 3: Os casos mais apontados na segunda resposta sobre parentes de quem mais gosta

\begin{tabular}{|l|c|c|}
\hline tia materna & 58 & $14,57 \%$ \\
\hline avó materna & 54 & $1357 \%$ \\
\hline primo materno & 37 & $9,30 \%$ \\
\hline Lio materno & 34 & $854 \%$ \\
\hline prima materna & 33 & $8,29 \%$ \\
\hline
\end{tabular}


Tabela 3a: Soma da segunda resposta sobre parente de quem mais gosta por lado de parentesco

\begin{tabular}{|l|r|c|}
\hline soma dos parentes do iado malemo & 245 & $61,56 \%$ \\
\hline soma dos parentes do lado paterno & 124 & $31,15 \%$ \\
\hline irmäos casados, cunhados, sobrinhos & 4 & $1,01 \%$ \\
\hline serm resposta & 25 & $628 \%$ \\
\hline Total & 398 & $100,00 \%$ \\
\hline
\end{tabular}

Tabela 4: 0s casos mais apontados na terceira resposta sobre parentes de quem mais gosta

\begin{tabular}{|l|c|c|}
\hline ta materna & 48 & $12,06 \%$ \\
\hline primo materno & 46 & $11,56 \%$ \\
\hline prima materna & 43 & $10,80 \%$ \\
\hline avé materna & 32 & 8,04 \\
\hline tia paterna & 31 & $7,79 \%$ \\
\hline
\end{tabular}

Tabela 4a: Soma da terceira resposta sobre parentes de quem mais gosta por lado de parentesco

\begin{tabular}{|l|c|c|}
\hline soma dos parentes do lado materno & 223 & $56,03 \%$ \\
\hline somá dos parentes co laco paterno & 117 & $29.40 \%$ \\
\hline irmăos casados, cumbados sobrinhos & 5 & $1,25 \%$ \\
\hline sem resposta & 53 & $13,32 \%$ \\
\hline Total & 398 & $100,00 \%$ \\
\hline
\end{tabular}

O terceiro parente mais mencionado apresentou, entre as cinco categorias com maior freqüència, a distribuição contida na tabela 4.

Agrupando-se os itens de toda a distribuição, segundo o lado de parentesco, vemos, conforme a tabela $4 a$, que o total de parentes do lado materno cai, em relação à distribuição anterior (tabela 3a), 5,5 pontos percentuais; mas o total do lado paterno também cai, embora menos $(1,75 \%)$. Ambas as diferenças são absorvidas pelos casos sem resposta, que aumentam sete pontos percentuais.

Isso significa que, ante a alternativa de colocar outros parentes na terceira resposta (e estes seriam, mais provavelmente, os do lado paterno, posto que os do lado materno já devem ter comparecido nas duas primeiras respostas), ou deixar em branco, muitos preferiram a segunda alternativa. Apontamos essa tendência, não porque represente muita coisa numericamente, mas porque reforça a consistência entre as diversas respostas analisadas até aqui.

Um balanço das distribuições apresentadas pelas três respostas à pergunta 2 leva à seguinte comclusão: a somatória das freqüências das respostas apontando o lado materno, embora oscile ligeiramente, coloca-se no patamar do dobro da somatória para o caso do lado paterno. Fsgotados os parentes do lado materno, quem concorre com os parentes do lado paterno, já na segunda resposta (tabela 3 a), é a categoria "não responde" c essa tendência se reforça na terceira resposta (tabela 4a).
A distribuição das respostas à terceira pergunla do questionário ("Qual o parente que você mais visita?"), nas cinco categorias com freqüências mais altas, encontra-se na tabela 5 , e as somas dos casos por lado de parentesco aparece na tabela 5a, cuja distribuição continua praticamente a mesma das três respostas à primeira pergunta (o parente de quem você mais gosta).

Entretanto, algo de novo aparece na tabela 5: a avó paterna aparece em terceiro lugar $\epsilon$, em quarto, a tia paterna. As respostas a esta pergunta (parente que você mais visita) interessam-nos de maneira especial porque refletem um comportamento individual c autônomo do jovem: ir em visita à casa de parentes. A melhor cotaçĩo dos parentes do lado paterno nessas respostas assume, portanto, um significado mais importante. Aqui nos ocorrem duas explicações possíveis:

a) livre de qualquer injução, o jovem exprime seus descjos pessoais indo visitar certos parentes;

b) responde a cobranças dos parentes do lado paterno, principalmente das mulheres (avó paterna c tia paterna).

Sem querer lorcer os fatos a favor da nossa hipótese, a segunda alternativa nos parece mais plausivel, tendo em vista que foi justamente nas respostas sobre os mais queridos. que também não dependeram de nenhuma injunção, que a cotação da família paterna es- 
teve pior do que no caso das visitas feitas pelos respondentes.

Na quarta pergunta, o questionário repete o formato da primeira (colocando no plural: "Quais os parentes que mais freqüentam sua casa?") e neste caso não se pedem três parentes, como na primeira pergunta, mas há trós linhas em branco, no questionário, para a res- posta. Temos, então, três distribuições para aprescntar e analisar para esta quarta questão.

A tabcla 6, mostra como, na primeira linha, os cinco primciros lugares foram ocupados e a tabela 6 a fornece as somatórias por lado de parentesco. As tabelas 7 e $7 a$, e 8 e 8 a apresentam os resultados correspondentes, obtidos para a segunda e a terceira linhas, respoctivamente

\section{Tabela 5: Parentes mais visitados}

\begin{tabular}{|l|c|c|}
\hline avô materna & 107 & $26,88 \%$ \\
\hline Lia naterna & 86 & $21,61 \%$ \\
\hline avó palerna & 45 & $11,31 \%$ \\
\hline lla palerria & 34 & $8,54 \%$ \\
\hline tio materno & 19 & $4,77 \%$ \\
\hline
\end{tabular}

Tabela 5a: Soma dos parentes mais visitados por lado de parentesco

\begin{tabular}{|l|c|c|}
\hline soma dos parontes do lado materno & 252 & $63,32 \%$ \\
\hline soma dos parentes do ado patcrno & 121 & $30,40 \%$ \\
\hline itmãos casados, cunhados e sobrinhos & 5 & $1,26 \%$ \\
\hline Sern resposta & 20 & $503 \%$ \\
\hline Total & 398 & $100,00 \%$ \\
\hline
\end{tabular}

Tabela 6: Parentes que mais freqüentam sua casa

\begin{tabular}{|l|c|c|}
\hline tia materna & 100 & 25,13 \\
\hline avó matcrna & 77 & $\frac{19 \%}{35 \%}$ \\
\hline lia paterna & 39 & $980 \%$ \\
\hline Drima materna & 2.3 & $578 \%$ \\
\hline Lo materno & 22 & $5,53 \%$ \\
\hline
\end{tabular}

Tabela 6a: Soma dos parentes que mais frequientam por lado de parentesco

\begin{tabular}{|l|c|c|}
\hline Soma dos parentes do tado naterno & 249 & $62,56 \%$ \\
\hline soma dos parentes do lado paterno & 109 & $27,38 \%$ \\
\hline irnäos casados, curhthados e sobrinhos & 7 & $1,77 \%$ \\
\hline sem resposta & 33 & $8,29 \%$ \\
\hline Total & 398 & $100,00 \%$ \\
\hline
\end{tabular}

Tabela 7: Segunda resposta para parentes que mais freqüentam

\begin{tabular}{|l|c|c|}
\hline tia materna & 56 & $14,07 \%$ \\
\hline avć rnáerna & 42 & $5,55 \%$ \\
\hline tio materno & 42 & $10,55 \%$ \\
\hline ta jaterrld & 33 & $8,29 \%$ \\
\hline tio patẹno & 26 & $6,53 \%$ \\
\hline
\end{tabular}

Tabela 7a: Soma da segunda resposta sobre parentes que mais freqüientam por lado de parentesco

\begin{tabular}{|l|c|c|}
\hline soma cos parentes do lado materno & 208 & $52,26 \%$ \\
\hline scma dos parentes do ado paterno & 110 & $27,64 \%$ \\
\hline irmans casados cunthados, sobrinhos & 9 & $2,26 \%$ \\
\hline serı lesposta & 71 & $17,84 \%$ \\
\hline Total & 398 & $100,00 \%$ \\
\hline
\end{tabular}


Tabela 8: Terceira resposta sobre parentes que mais freqüentam

\begin{tabular}{|l|c|c|}
\hline tia materna & 43 & $10,80 \%$ \\
\hline primo materno & 34 & $8.54 \%$ \\
\hline avó materna & 27 & $6.78 \%$ \\
\hline prino paterno & 25 & $628 \%$ \\
\hline
\end{tabular}

Tabela 8a: Soma da terceira resposta sobre parentes que mais freqüentam por lado de parentesca

\begin{tabular}{|l|c|c|}
\hline soma dos parentes do tado materno & 162 & $40,70 \%$ \\
\hline scma cos parentes do lado vatem & 36 & $21,61 \%$ \\
\hline imâos casados, cunhados, sobriahos & 4 & $1,01 \%$ \\
\hline scm rosposta & 146 & $36,68 \%$ \\
\hline Total & 398 & $100,00 \%$ \\
\hline
\end{tabular}

Tabela 9: Qual o parente que viu ou falou ao telefone por último

\begin{tabular}{|l|c|c|}
\hline tia matorna & 82 & $20,60 \%$ \\
\hline avó materna & 55 & $13,82 \%$ \\
\hline tia pazerna & 40 & $10,05 \%$ \\
\hline vrima materna & 32 & $8,04 \%$ \\
\hline tio materno & 31 & $7,79 \%$ \\
\hline
\end{tabular}

Tabela 9a: Soma dos parentes que viu ou falou ao telefone por último por lado de parentesco

\begin{tabular}{|l|r|c|}
\hline soma dos parentes do lado materno & 238 & $59,80 \%$ \\
\hline sorna dos parentes do lado paterno & $12 \%$ & $31,90 \%$ \\
\hline irmäos casados, cunhados, sobrinhos & 4 & $1,01 \%$ \\
\hline sem resposta & 29 & $7,29 \%$ \\
\hline Total & 398 & $100,00 \%$ \\
\hline
\end{tabular}

Tabela 10: Soma das respostas sobre preferências afetivas e convivência

\begin{tabular}{|l|c|c|}
\hline soma dos parentes do lado materno & 1857 & $58,32 \%$ \\
\hline soma dos parentes do ado paterno & 899 & $28,2,3 \%$ \\
\hline irmåos casados, cunhados, sobrinhos & 40 & $1,26 \%$ \\
\hline sem resposta & 388 & $12,19 \%$ \\
\hline Total & 3184 & $100,00 \%$ \\
\hline
\end{tabular}

A tendência já apontada na análise dos parentes mais queridos reaparece aqui: proporcionalmente, o lado materno continua constituindo dois terços do total, deixando um terço para o lado paterno. Mas como em termos absolutos ambas as somas caem, da primeira à terceira respostas, a diferença é absorvida pelos casos sem resposta. Na distribuição da terceira resposta (tabela 8a), o total dos "sem resposta" é muito maior (quase o dobro) que o total de parentes do lado paterno.

As preferências afetivas e os padrões de convivência em relação aos parentes foram, por último, abordadas ainda por outro ângulo, através da pergunta de número cinco: "Qual o parente que você viu ou falou ao telefone por último?" Os cinco primeiros postos na distribuição das respostas estão na tabela 9 .
Repetindo o processo de agrupamento por lado, lemos os resultados na tabela 9 a.

No essencial, tudo permanece na mesma. Assim, fechamos o bloco das preferências com uma distribuição que reforça as conclusões sugeridas pelas anteriores.

Uma visão global das preferencias afetivas e padrões de convivência pode ser fornecida pela soma de todas as respostas que se referem a esses fatores no questionário -... três res postas para "parenles de quem mais gosta", uma resposta para "parentes que mais visita", três respostas para "parentes que mais freqüentam sua casa" e uma resposta para "qual foi o parente que viu ou falou ao telefone por último" - isto é, a soma das tabelas $2 a, 3 a$, $4 a, 5 a, 6 a, 7 a, 8 a$ e $9 a$, soma esta que se encontra na tabela 10 . 
Tabela 11: Soma das respostas sobre preferências afetivas e convivência por lado de parentesco na subamostra

\begin{tabular}{|l|r|c|}
\hline soma dos parcintos do lado rlaterno & 338 & $6402 \%$ \\
\hline soma dos parontes do lado paterno & 149 & $28.21 \%$ \\
\hline irmäus Casadacs, cunhados, sobrinhos & 3 & $0.57 \%$ \\
\hline sem resposta & 38 & $7,20 \%$ \\
\hline Total & 528 & $100,00 \%$ \\
\hline
\end{tabular}

Tabela 12: Preferências afetivas e padrões de convivência por gênero

\begin{tabular}{|c|c|c|c|}
\hline \multirow{2}{*}{ TIPO DE PARENTESCO } & \multicolumn{2}{|c|}{ SEXO } & \multirow{2}{*}{ TOTAL } \\
\hline & MASC. & FEM. & \\
\hline soma dos parer es do ado materro & $\begin{array}{c}157 \\
55.12 \% \\
\end{array}$ & $\begin{array}{c}181 \\
62,85 \% \\
\end{array}$ & 338 \\
\hline somla dus parenles do lado paterno & $\begin{array}{c}62 \\
25.83 \% \\
\end{array}$ & $\begin{array}{c}87 \\
30,21 \%\end{array}$ & 149 \\
\hline Irmüos casados, cu rhados e sobrinhos & - & $\begin{array}{c}3 \\
1,04 \%\end{array}$ & 3 \\
\hline sem resposta & $\begin{array}{c}21 \\
8,75 \% \\
\end{array}$ & $\begin{array}{r}17 \\
5,90 \% \\
\end{array}$ & 38 \\
\hline Total & $\begin{array}{c}210 \\
10000 \%\end{array}$ & $\begin{array}{c}288 \\
100,00 \%\end{array}$ & 528 \\
\hline
\end{tabular}

Tabela 13: Distribuição da amostra por idade

\begin{tabular}{|l|c|c|}
\hline 1718 anos & 138 & $34,67 \%$ \\
\hline 1920 anos & 162 & $10,70 \%$ \\
\hline 2122 anos & 61 & $15,33 \%$ \\
\hline $23-21$ anos & 20 & $5,03 \%$ \\
\hline acima de 25 anos & 16 & $4,02 \%$ \\
\hline Tola resposta & 1 & $0,25 \%$ \\
\hline
\end{tabular}

A fim de afastar outras influências, tais como separação domiciliar da família nuclear e ausência de ambos os lados da família extensa morando na mesma cidade que a família nuclear, selecionamos apenas os casos que moram com a família nuclear e lêm todos os tipos de parentes, de ambos os lados, morando na cidade de São Paulo. Essa subamostra da qual já falamos se constituiu de 66 entrevistados. A soma global para todas as respostas deste bloco apresentou para a subamostra proporçŏes que se repetiram mais uma vez, como podemos ver na tabela 11 .

Fizemos incidir sobre a subamostra de 66 casos a investigação sobre possiveis variações por gênero. O total de 528 respostas para todas as perguntas do bloco "preferências afetivas e padrões de convivência", quando discriminado por gênero, está na tabela 12 .

A revelaçăo trazida pela tabela 12 é a seguinte: o lado paterno recebe cinco pontos percentuais a mais de respostas femininas. Tal diferença não leva a nada de conclusivo, no contexto em que se dá. Se fosse possível aplicá-lo, um teste estatístico daria essa diferença como significativa?

Quanto à variável idade, houve uma concentração tão intensa nas primeiras três calegorias de faixa etária que não se cogitou de um cruzamento com a variável principal, uma ve $\angle$ que a variação total da reunião dessas três faixas equivalia a cinco anos, período muito curto de tempo para surgirem mudanças.

A distribuição pormenorizada por faixas etárias está na tabela 13.

A origem e a ctnia do respondente pareceu-nos uma variável muito importante na definição de uma dominação matriarcal ou patriarcal nos padrões familiares. Cercamos essa variável das seguintes formas: local de nascimento do pai, da mãe, da avó matcrna, do avô materno, da avó paterna e do avô paterno. 
A tabela 14 mostra o local de nascimento dos pais, e a tabela 15, o das avós.

Procuramos uma eventual influência da etnia sobre a variável dependente utilizando como referência a origem dos avós. Nesta última variável, os tipos "puros" (quatro avós de uma mesma nacionalidade ou etnia) foram considerados os mais propícios para alguma indicação. Como podemos verificar na distribuição da origem dos avós (tabela 15), os únicos casos "puros" que, numericamente, se prestavam a um cruzamento com a variável "preferência afetiva e padrões de convivência" eram: "quatro avós brasileiros" e "quatro avós asiáticos".
Vejamos, na tabela 16, como se distribuem as 1136 respostas (142 casos com oito respostas cada um) dos respondentes com quatro avós brasileiros da amostra; a tabela 16a fornece a distribuição das respostas dos 24 casos com avós brasileiros da subamostra de 66 (que moram com a família nuclear e têm todos os tipos de parentes morando na cidade de São Paulo).

Como vemos, a distribuição das respostas para os que têm os quatro avós brasileiros na amostra global (tabela 16) é muito parecida com as encontradas até aqui. Entretanto, se compararmos essa distribuição com a obtida

Tabela 14: Distribuição do local de nascimento dos pais

\begin{tabular}{|c|c|c|}
\hline ambos brasileiros & 305 & $76,63 \%$ \\
\hline arrbus asiálicos (japoneses, coreancs e chineses) & 17 & $4,27 \%$ \\
\hline ambos talino-americanos ou curopeus & 16 & $4,02 \%$ \\
\hline mãe bräsileira/pai lalino-americano ou europeu & 15 & $377 \%$ \\
\hline măe brasileira/pai asiático & 7 & $1,76 \%$ \\
\hline mâe, latino-anternca'la uu europeia/pai brasileiro & 6 & $151 \%$ \\
\hline mä́l asiälica/pai brasileiro & 3 & $0.75 \%$ \\
\hline outros e sem resposta & 29 & $7,29 \%$ \\
\hline Total $=$ & 398 & $100,00 \%$ \\
\hline
\end{tabular}

Tabela 15: Origem dos avós

\begin{tabular}{|l|c|c|}
\hline 4 avós braśleiros & 142 & $35,68 \%$ \\
\hline 4 dvos aśálicos & 57 & $1432 \%$ \\
\hline 4 avós latino-americanos ou europerts & 21 & $5,27 \%$ \\
\hline 3 dos avós brasileros & 41 & $10,30 \%$ \\
\hline 3 dos avós latino-americanos ou europeus & 6 & $1.51 \%$ \\
\hline 3 dos avós asiáticos & 6 & $1,51 \%$ \\
\hline 2 dos avós brasileiros & 72 & $18,09 \%$ \\
\hline outros e sem resposta & 53 & $13,3 \%$ \\
\hline Total & 398 & $100,00 \%$ \\
\hline
\end{tabular}

Tabela 16: Soma das preferências afetivas e da convivência por lado de parentesco entre os casos com quatro avós brasileiros na amostra

\begin{tabular}{|l|c|c|}
\hline soma dos parentes do lado materio & 698 & $61.44 \%$ \\
\hline soma dos parentes do sado patcrno & 316 & $27,82 \%$ \\
\hline irmäos casados, cunhados, sobrinhos & 13 & $1,14 \%$ \\
\hline sem resposta & 109 & $9,60 \%$ \\
\hline Total & 1136 & $100,00 \%$ \\
\hline
\end{tabular}

Tabela 16a: Soma das preferências afetivas e da convivência por lado de parentesco entre os casos com quatro avós brasileiros na subamostra

\begin{tabular}{|c|c|c|}
\hline soma dos parentes do lado materno & 135 & $70.31 \%$ \\
\hline soma dos parentes do lado paterno & 50 & $2604 \%$ \\
\hline irmảos casados, cunhados, sobrinhos & - & 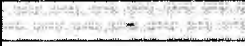 \\
\hline sem resposta & 7 & $3.65 \%$ \\
\hline Total & $192^{*}$ & $900,00 \%$ \\
\hline
\end{tabular}

* 24 casos, comi oito respostas cada urm. 


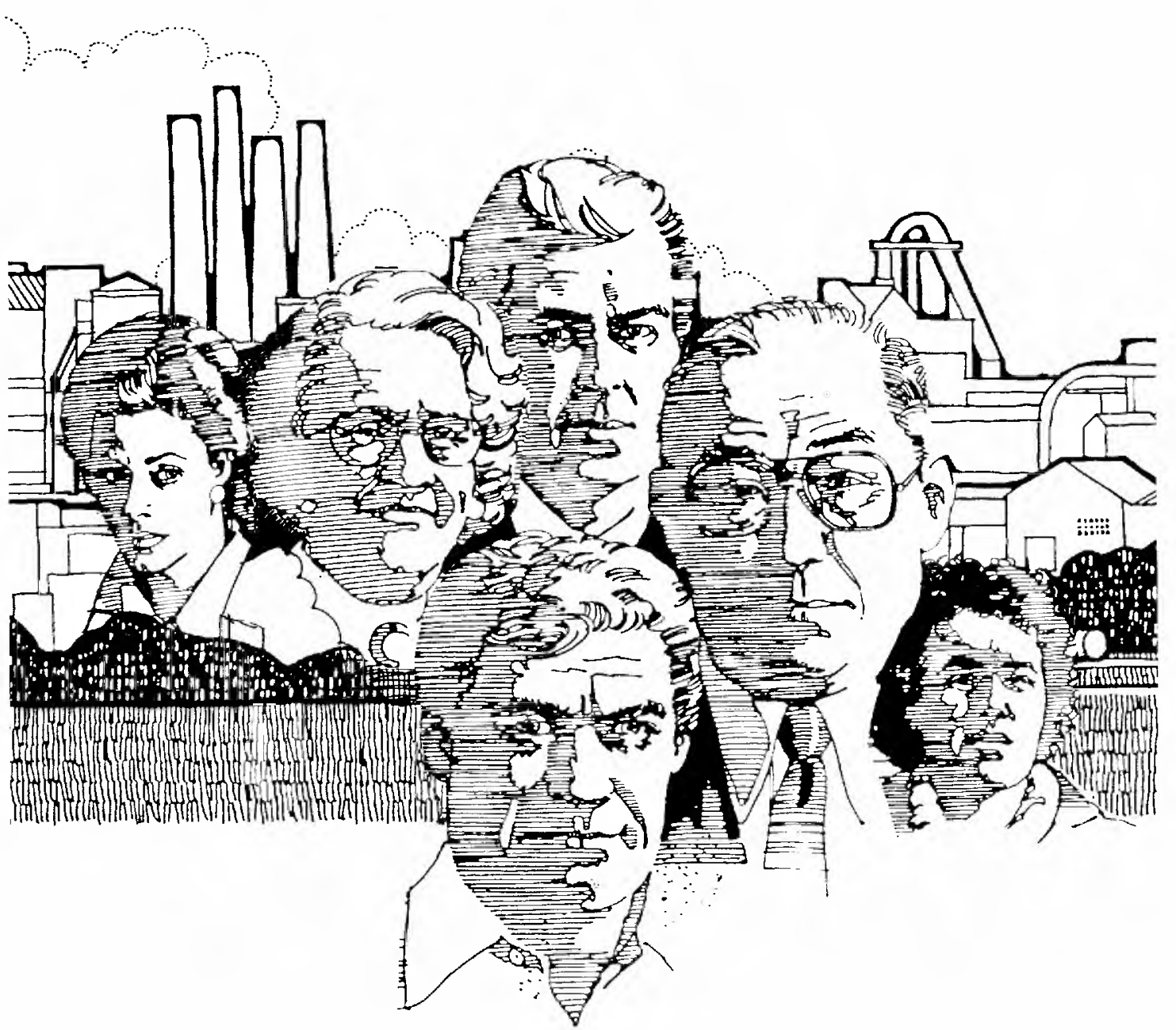

Tabela 17: Soma das preferências afetivas e da convivência por lado de parentesco entre os casos com quatro avós asiáticos na amostra

\begin{tabular}{|l|c|c|}
\hline soma dos parentes do lado materno & 224 & $49,13 \%$ \\
\hline soma dos parentes do lado paterno & 126 & $27,63 \%$ \\
\hline imäos casados, cunhados e sobrintos & 12 & $2,63 \%$ \\
\hline sem resposta & 94 & $20,61 \%$ \\
\hline Tolal & $456^{*}$ & $100,00 \%$ \\
\hline
\end{tabular}

${ }^{x}$ y $/$ casos com oito respostas cada uri

na subamostra (tabela 16a), verificamos uma elevação de nove pontos percentuais a favor do lado materno e uma queda de quase dois pontos no lado paterno.

A outra investigação possível, como já mencionamos, relere-se aos casos com quatro avós asiáticos (japoneses, coreanos e chineses).

Na distribuição desses casos, apresentada pela tabela 17, encontramos a melhor posição, de todas as analisadas até agora, do lado paterno, nos dados da amostra global.

() mesmo cruzamento feito com a subamostra de 66 casos, onde aparecem once entrevistados com quatro avós asiáticos, reforça ainda mais a tendência favorável ao lado paterno, conforme se vê na tabcla 17 a.
Fazendo um grande balanço de todas as respostas sobre parentesco, isto ć, colocando todos os resultados obtidos atć agora em presença, teremos uma visão mais global sobre essa investigação.

O quadro 1 apresenta um conjunto de "indices" que resulta da divisão dos números obtidos para o lado materno pelos números obtidos para o lado paterno em cada pergunta. Assim, um indice de valor 2,00 significa que a soma para o lado materno é duas vezes maior que a soma para o lado paterno.

Como vemos, o índice mais alto (isto é, a maior vantagem para o lado maternol foi encontrado nos casos que têm quatro avós brasi- 
Tabela 17a: Soma das preferências afetivas e da convivência por lado de parentesco entre os casos com quatro avós asiáticos na subamostra

\begin{tabular}{|c|c|c|}
\hline soma dos parentes do lado materno & 49 & $55,68 \%$ \\
\hline soma dos parentes do lado paterno & 33 & $37,50 \%$ \\
\hline irmãos casados, cunnados, sobrinhos & - & - \\
\hline sem resposta & 6 & $6.82 \%$ \\
\hline Tolat & $88^{*}$ & $100,00 \%$ \\
\hline
\end{tabular}

* 11 casos, com oito resposas caca um.

\section{Quadro 1: Lado materno/lado paterno}

\begin{tabular}{|c|c|}
\hline $1^{2}$ resposta para a $1^{a}$ pergunta (parente de quem mais gosta) & 267 \\
\hline $2^{4}$ resposta para a pergunta (parerto de quem mais gosta) & 198 \\
\hline $3^{*}$ resposta para a $1^{1}$ pergunta (parente de quem mais gosta) & 191 \\
\hline Resposta para a segunda pergurta (parente a je rais visita) & 208 \\
\hline $1^{\text {a }}$ resposta para a $3^{\mathrm{a}}$ pergunta (parentes que mais freqúentalin sua casa) & 228 \\
\hline $2^{4}$ respesta para a $3^{a}$ pergunla (pare tes que rlais requertlarn sua casa) & 180 \\
\hline $3^{2}$ Tesposta para a $3^{n}$ pergunta (parentes que jats trequentam sua casa) & 1,88 \\
\hline Respostas para a 41 pergunta (qual o parenta sue viu ou talou ao toletone por úlimo) & 187 \\
\hline Total para a amostra global (3.184 respostas) & 206 \\
\hline Total para a subamostra (528 respostas) & 227 \\
\hline Total para os homens na subamcstra & 253 \\
\hline Total para as mulheres na subamostra & 208 \\
\hline Total para os que têm 4 avós brasileiros na amostra. & 221 \\
\hline Total para os que :êm A avós brasilerros na subemostra & 270 \\
\hline Total para os que têm 4 avós as láticos na amostra & 178 \\
\hline Iotal pard us que Eerr 4 avos asiádicos nid SL barmostra & 148 \\
\hline Média de todos us ind ces apresentadus & 2,10 \\
\hline Vuriaçàn entre todos os indicas apresentaros & 122 \\
\hline
\end{tabular}

leiros na subamostra $(2,70)$, o mais baixo $(1,48)$ nos casos com quatro avós astáticos na subamostra.

Os pontos extremos encontrados na amostra global foram: 2,67 - primeira resposta para a primeira pergunta (parente de quem mais gosta) de um lado; e 1,78- somatória das respostas dos casos com quatro avós asiáticos, de outro lado. Portanto, tomando-se a amostra slobal, a variação total encontrada foi de 0,89 .

Resta-nos, agora, estudar as respostas sobre empresas familiares. Entre os respondentes, 113 casos apontaram a existência de empresas familiares em sua família; destes, 76 indicaram apenas uma e 37 duas empresas.

A composiçăo de propriedade para a primeira empresa mencionada se distribui conforme mostra a tabela 18 . Nela se vê que os casos onde filhas mulheres não entram somam $53,32 \%$ (irmãos homens $31,20 \%$; pai e filhos homens 15,04\%; mâe e fillos homens $5,31 \%$; tio paterno e sobrinho $1,77 \%$ ). A mulher está presente com os irmáos mas sem nenhum dos pais, em 6,20\% dos casos e ao lado do marido e do irmão deste em $0,89 \%$ dos casos. Em outros, a presença da mulher se dá através do marido: pai, filho e genros, 1,77\%; co-cunhados homens, $0,89 \%$. sogro, genro e netos, $0,89 \%$. Associaçoes entre mulheres apa recem duas veres envolvendo irmás e uma vez envolvendo màe efilha.

A segunda empresa mencionada $\mathrm{cm} 37 \mathrm{ca}-$ sos obedece à distribuição apresentada na tabela 19, quanto à composiçāo dos proprietários.

As observaçōos que podem ser feitas sobre a segunda empresa são pralicamente as mesmas já elaboradas para a primeira empresa.

O tipo de composição de proprietários nas empresas familiares é uma informaçâo a que temos acesso por muitas outras vias além dos dados do questionário desta pesquisa e já sabiamos, ao formularmos o projeto deste trabalho, que se tratava de um assunto do homens, ficando, na maior parte das vezes, as mulheres da fratria excluidas do procosso.

O que esta pesquisa tray de original a a verificação da predominância do lado materno na circulaça do ateto e nos padróes de convivência nas famílias extensas. O confronto dessa realidade com o padrão de composição de propriedade das empresas familiares, e a existência de uma incompatibilidade, nesse aspecto, entre os dois sistemas de fronteiras coincidentes que compöem a empresa familiar, 
Tabela 18: Composição da propriedade de empresas familiares para a empresa 1

\begin{tabular}{|c|c|c|}
\hline irmàos homens & 36 & $31,20 \%$ \\
\hline pai e fithos homens & 17 & $1504 \%$ \\
\hline Casal & 14 & $1239 \%$ \\
\hline curnados homens & 8 & $708 \%$ \\
\hline 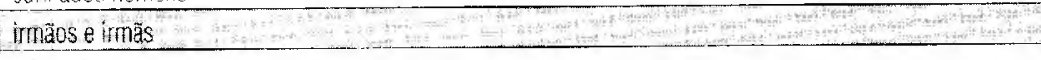 & -1 & $6.20 \%$ \\
\hline made $e$ lilhus nomens & 6 & $5,31 \%$ \\
\hline Casal tho(s) e liha(s) & 3 & $2,65 \%$ \\
\hline duas irmās e seus maridos & 2 & $1,77 \%$ \\
\hline tio paterno e sobrintho & . & $1,77 \%$ \\
\hline pai, fillho e genros & 2 & $1,77 \%$ \\
\hline 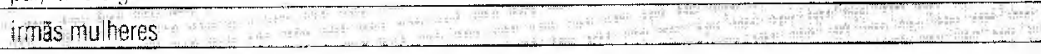 & 2 & $1,77 \%$ \\
\hline Co-cuntiados homens & 1 & $0,89 \%$ \\
\hline Soyro genro e neto & 1. & $0,89 \%$ \\
\hline dois mianos e a mulher do um doiss & 1 & $0,89^{\circ}$ \\
\hline mäe e filha & 1 & $0,89 \%$ \\
\hline adi thoe filld & 1 & $0.89 \%$ \\
\hline casal e gento & 1. & $0.89 \%$ \\
\hline antros & 8 & $708 \%$ \\
\hline 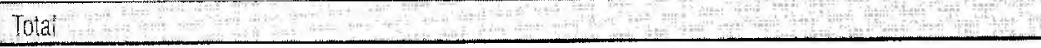 & 113 & $10000 \%$ \\
\hline
\end{tabular}

Tabela 19: Composição da propriedade de empresas familiares para a empresa 2

\begin{tabular}{|c|c|c|}
\hline - & 12 & $32,43 \%$ \\
\hline par of fithos homens & 6 & $16,22 \%$ \\
\hline casal $\quad$ con & 4 & $10,81 \%$ \\
\hline casal, filho(s) ofitha(s) & 2 & $5,41 \%$ \\
\hline co-cunhados homens & 2 & $5,41 \%$ \\
\hline imăs e imráos & 2 & $5,41 \%$ \\
\hline 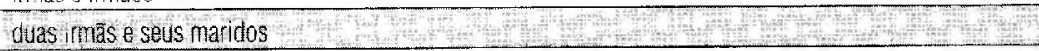 & (1) & $2,70 \%$ \\
\hline mãe e fillhos homens & 1 & $2,70 \%$ \\
\hline cunhados homens & 1 & $270 \%$ \\
\hline mäe e fitha & 1 & $270 \%$ \\
\hline outros $\quad$. & 5 & $13.51 \%$ \\
\hline Total & 37 & $10000 \%$ \\
\hline
\end{tabular}

foi a hipótese que colocamos à prova. Embora não tenhamos construído um teste de hipótese, apareceram indicações consistentes entre si, que nos permitem considerar os resultados fortemente sugestivos.

Concluindo, tudo parece levar a crer que as duas hipóteses que levantamos parecem ter, através desta pesquisa, fortes razōes para ser verdadeiras, apesar do caráter pouco rigoroso da amostra:

a) as preferências afetivas e a convivência na família extensa se dão preferencialmente numa razão de dois terços a seu favor - com o lado materno;

b) as empresas familiares se organizam, de preferência, entre parentes do lado paterno. lembrando que o mesmo grupo de pessoas está ao mesmo tempo envolvido numa família extensa e numa empresa familiar, encontramos, entre as outras já apontadas por outros autores, mais uma incompatibilidade entre esses dois sistemas de fronteiras coincidentes. Assim como as demais, essa incompatibilidade pode gerar efeitos na empresa familiar e na família. Viver a situação na qual os parentes de que se gosta menos são justamente os sócios, esposas e filhos dos sócios do pai constituiria, no caso de nossas hipóteses serem verdadeiras, um constrangimento de tipo emocional, nem sempre contornável da maneira mais feliz do ponto de vista da família, ou da maneira mais eficiente, do ponto de vista da empresa. 


\section{ANEXO 1}

\section{QUESTIONÁRIO}

1. Com quem você mora?

(Indique, nas linhas abaixo, por parentesco (por exemplo: pai, mãe etc.) ou por tipo de relacionamento (por exemplo, amigo etc.).

Se houver parentes na lista que você escreveu acima (sem contar pais e irmãos), indique, para cada um, se são do lado materno ou paterno.
a)
() lado materno
() lado paterno
b).
() lado materno
() lado paterno
c)
() lado materno
() lado paterno

2. Excluindo seus pais e irmãos, quais os três parentes de quem você mais gosta? (Tipo de parentesco: tia, avo, primo etc.)
a).
() lado materno
() lado paterno
b).
() lado materno
() lado paterno
c).
() lado materno
() lado paterno

3. Qual o parente que você mais visita? (Tipo de parentesco: tia, avó, primo etc.)

() lado materno

() lado paterno

4. Quais os parentes que mais freqüentam sua casa? (excluindo os que moram com você) (Tipo de parentesco: tia, avó, primo etc.)

() lado materno

() lado materno

() lado materno

() lado paterno

() lado paterno

() lado paterno

5. Qual foi o parente (excluindo os que moram com você) que você viu ou falou por telefone por último? (Tipo de parentesco: tia, avó, primo etc.)

() lado materno

() lado paterno

6. Entre seus parentes, existem empresas familiares?

() existe uma

() existem duas

() existem mais de duas () não existem

Se não existem, pule para a pergunta 7.

Se existem, assinale na lista abaixo quem são os donos. Se

existirem mais de duas empresas, escolha as duas principais.

\section{EMPRESA 1:}
() avô materno
() avó materna
() avô paterno
() avó paterna
() tio materno
() tia materna
() tio paterno
() tia paterna
() pai
() mãe
() irmão
() irmã

() você

() tio casado com tia materna

() tia casada com tio materno

() tio casado com tia paterna

() tia casada com tio paterno

() primo do lado materno

() primo do lado paterno

() cunhado (marido de sua irmã)

() cunhada (esposa de seu irmão)

Observação: Se houver mais de uma pessoa do mesmo grau de parentesco na direção da empresa (por exemplo, dois tios paternos), assinale o número dois no espaço correspondente a tio paterno.

\section{EMPRESA 2:}

$\begin{array}{ll}\text { () avô materno } & \text { () irmã } \\ \text { () avó materna } & \text { () você } \\ \text { () avó paterna } & \text { () tio casado com tia materna } \\ \text { () avô paterno } & \text { () tia casada com tio materno } \\ \text { () tio materno } & \text { () tio casado com tia paterna } \\ \text { () tia materna } & \text { () tia casada com tio paterno } \\ \text { () tio paterno } & \text { () primo do lado materno } \\ \text { () tia paterna } & \text { () primo do lado paterno } \\ \text { () pai } & \text { () cunhado (marido de sua irmã) } \\ \text { () mãe } & \text { () cunhada (esposa de seu irmão) } \\ \text { () irmão } & \end{array}$

7. Indique sua idade e sexo.

...........anos de idade () sexo masculino () sexo feminino

8. Em que país nasceram seus pais?

pai...

mãe

9. Em que país nasceram seus avós?

avô materno

avó materna

avô paterno

avó paterna.

10. Indique quais dos parentes abaixo moram na cidade de São Paulo.
() pai
() mãe
() irmãos
() avós maternos
() tios maternos
() tios paternos
() avós paternos
primos maternos
() primos paternos
() primos paternos 